\title{
Ventilatory and Metabolic Demands During Aggressive Physical Restraint in Healthy Adults
}

\begin{abstract}
We investigated ventilatory and metabolic demands in healthy adults when placed in the prone maximal restraint position (PMRP), i.e., hogtie restraint. Maximal voluntary ventilation (MVV) was measured in seated subjects $(n=30)$, in the PMRP, and when prone with up to 90.1 or $102.3 \mathrm{~kg}$ of weight on the back. MVV with the heaviest weight was $70 \%$ of the seated MVV (122 \pm 28 and $156 \pm 38 \mathrm{~L} / \mathrm{min}$, respectively; $p<0.001)$. Also, subjects $(n=27)$ were placed in the PMRP and struggled vigorously for 60 sec. During the restrained struggle, ventilatory function $\left(\dot{V}_{\mathrm{E}} / \mathrm{MVV}\right)$ was $44 \%$ of MVV in the resting PMRP. While prone with up to 90.1 or $102.3 \mathrm{~kg}$ on the back, the decrease in MVV was of no clinical importance in these subjects. Also, while maximally struggling in the PMRP, $\dot{V}_{\mathrm{E}}$ was still adequate to supply the ventilatory needs.
\end{abstract}

KEYWORDS: forensic sciences, maximal voluntary ventilation, minute ventilation, oxygen consumption, positional asphyxia

Law enforcement and prehospital care personnel often confront violent, dangerous individuals who must be physically restrained to ensure safety to themselves and to those around them. Authorities have developed a number of physical restraint techniques to control and subdue such individuals in the field $(1,2)$. One of these, the prone maximal restraint position (PMRP), also referred to as the hogtie or hobble restraint, has been used extensively by field personnel $(3,4)$. When in the PMRP, an individual is prone with his/her wrists secured behind the back, ankles bound together, and wrists and ankles tied together using handcuffs, cords, chains, or hobble devices $(3,5)$.

Reports of sudden deaths in individuals in the PMRP have appeared at least since the 1980s, which have created controversy regarding the safety of these restraint positions $(3,6-8)$. Some authors have suggested that the PMRP may prevent adequate chest and abdominal movement, which places the individual at risk of asphyxiation (7-9). Asphyxiation that is caused by body position has been referred to as "positional asphyxia" (10). However, a recent study reported that, although PMRP by itself resulted in a small, restrictive ventilatory pattern compared with seated measurements, there was no evidence of hypoventilation, hypercapnia, or hypoxemia (11).

Additionally, police officers often apply force to the back to better control an agitated person during the restraint process. This additional force has been hypothesized to constrict the chest and abdomen more than the PMRP alone (12-14) and lead to asphyxiation (15). Chan et al. (3) examined the effects on pulmonary function from 11.4 to $22.7 \mathrm{~kg}$ applied to the back of prone subjects. Although the PMRP with or without force applied to the back led to a restrictive pattern on pulmonary function testing, there was no evidence of hypoxia or hypercapnia.

\footnotetext{
${ }^{1}$ Department of Exercise and Nutritional Sciences, San Diego State University, San Diego, CA 92182.

${ }^{2}$ Department of Emergency Medicine, Medical Center, University of California, San Diego, CA 92103.

${ }^{3}$ San Diego State Heart Institute, San Diego State University, San Diego, CA 92182.

Received 11 Dec. 2005; and in revised form 19 June 2006; accepted 1 July 2006; published 8 Dec. 2006.
}

Nevertheless, it would be safe to assume that law enforcement officers are able, and do, apply more than $22.7 \mathrm{~kg}$ of force to the back of suspects placed in the PMRP, particularly if the individuals are violent. Cases of sudden death of restrained individuals often involve those who continued to struggle after being restrained (8). This study was undertaken to determine whether the use of force greater than $22.7 \mathrm{~kg}$ might inhibit ventilatory function such that it became a clinically important consideration in the analyses of such deaths. Moreover, we were interested in whether individuals struggling during periods of physical restraint were able to approach the limits of their ventilatory function. This study, which utilized a randomized, cross-over, controlled design, had two parts. For the first part, the effects on maximal voluntary ventilation (MVV) in subjects were examined while in the PMRP and while prone with up to $102.3 \mathrm{~kg}$ of weight positioned on their back. The second part of the study was an investigation of maximally struggling subjects while in the PMRP on cardiopulmonary measurements to determine the effect of PMRP on ventilatory function.

\section{Methods}

\section{Subjects}

Thirty volunteer male and female subjects were recruited to participate in the study. Exclusionary criteria included any history of pulmonary or cardiac disease (as screened with the Physical Activity Readiness-Questionnaire), current recreational drug use, or other significant illness or disability that would limit the ability to perform the exercise regimen required for the study. Each potential participant was screened before testing by a physician investigator to ensure that he/she was free of acute illness or injury. Also, urine specimens were collected and tested for the presence of the major metabolites of common drugs of abuse (i.e., phencyclidine, benzodiazepines, cocaine, amphetamines, THC, morphine, and barbiturates) and tricyclic antidepressants (Triage ${ }^{\circledR}$ Drugs of Abuse Panel plus Tricyclic Antidepressants Test, Biosite ${ }^{\mathbb{R}}$ Inc., San Diego, CA). Individuals were excluded if the immunoassay detected any of these substances in the urine. Informed consent was obtained from each individual before participation, 
and subjects who completed the study were given financial compensation. The experimental study design and protocol were approved by the San Diego State University and the University of California, San Diego Institutional Review Boards (IRB), and procedures were followed in accordance with the ethical standards established by the IRBs.

\section{Part 1-Position and Weight Effects on Maximal Voluntary Ventilation $(M V V)$}

The first part of the study evaluated the effects of subjects in the PMRP and when prone with varying weights on the back upon the MVV. A licensed American Thoracic Society (ATS) respiratory technician conducted all MVV testing (MedGraphics CPX/D System, Medical Graphics Corporation, St. Paul, MN), and each trial was repeated at least twice. Measurements were obtained in accordance with ATS standards for reproducibility and acceptability (16). Raw MVV data were normalized for age, height, gender, and race (17).

MVV was measured with subjects seated and while in the PMRP. In addition, MVV was measured with subjects prone and three different weights placed on the back. The order of these measurements was randomly chosen to negate possible order effects of repetitive testing. For the seated position, subjects sat on a chair without restraint with their feet flat on the ground and their back upright against the chair back. During the PMRP trial, subjects were placed prone on a gymnastic mat with the head turned to the side. The subjects' wrists and ankles were tightly bound together behind the back using a restraining fabric cuff (Fig. 1). The ankles and wrists were then bound together. This position was similar to the PMRP used in previous studies and case reports (11). For the prone trials with weights, a light (LW), moderate (MW), and heavy weight (HW) in the form of canvas bags, each filled with $11.4 \mathrm{~kg}$ of lead shot, were placed on subjects' backs. The canvas bags were evenly positioned between the posterior shoulders and mid back and secured by a custom-made vest worn by the subject that had straps to hold the canvas bags in place. As we theorized that law enforcement officials would apply less weight to the back when restraining a lighter individual, we used differing weights depending on the subject's weight. Subjects who weighed less than $68 \mathrm{~kg}$ were tested with $22.7 \mathrm{~kg}(\mathrm{LW})$, $56.8 \mathrm{~kg}(\mathrm{MW})$, and $90.9 \mathrm{~kg}(\mathrm{HW})$ while subjects weighing more than $68 \mathrm{~kg}$ were tested with $34.1 \mathrm{~kg}(\mathrm{LW}), 68.2 \mathrm{~kg}(\mathrm{MW})$, and $102.3 \mathrm{~kg}(\mathrm{HW})$. In all five conditions, MVV was measured

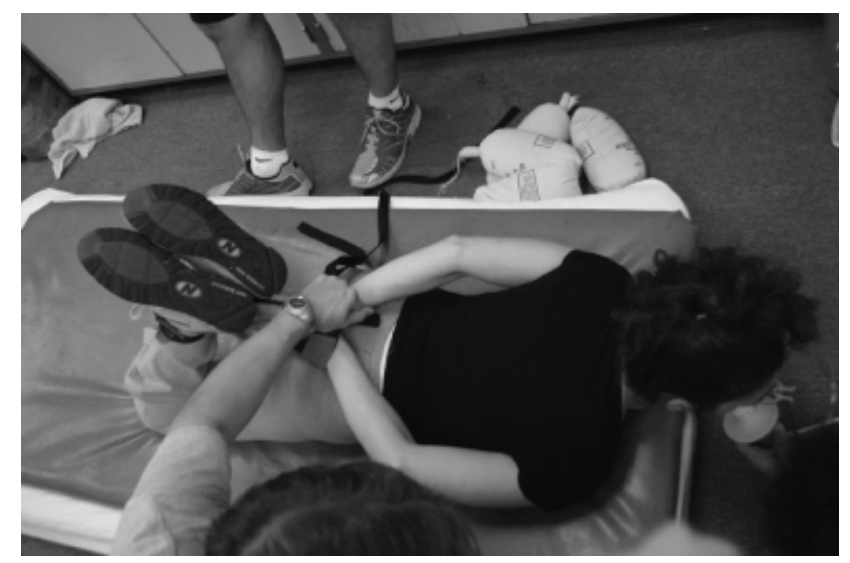

FIG. 1-Illustration of a subject in the prone maximal restraint position (PMRP). immediately upon positioning the subject. Between the trials, subjects rested in a seated position for $c .15 \mathrm{~min}$.

\section{Part 2-Cardiopulmonary Measurements During Maximal Struggle}

For the second part of the study, oxygen consumption $\left(\dot{V} \mathrm{O}_{2}\right)$, minute ventilation $\left(\dot{V}_{\mathrm{E}}\right.$; respiratory rate $\times$ tidal volume), and heart rate (HR) were measured during a 60-sec maximal struggle while subjects were in the PMRP. Pulmonary $\dot{V} \mathrm{O}_{2}$ is a measure of systemic oxygen utilization, which reflects the metabolic rate, and the maximal $\dot{V} \mathrm{O}_{2}\left(\dot{V} \mathrm{O}_{2 \max }\right)$ quantifies the aerobic capacity. Subjects were placed prone on a mattress elevated $c .40 \mathrm{~cm}$ from the floor. A face mask with a low-resistance two-way breathing valve was placed over the mouth and nose, and the subject was positioned, such that his/her head hung over the edge of the mattress and would not strike the floor or mattress during the struggle. An adhesive gel applied to the edge of the mask was used to prevent air leaks. The subjects' wrists and ankles were tightly bound together behind the back similar to the PMRP described above. Subjects then performed a maximal struggle - in an attempt to escape the restraint-for $60 \mathrm{sec}$ while cardiopulmonary measurements were taken (TrueMax 2400, Parvo Medics Inc., Sandy, UT). Verbal encouragement was provided throughout each test. Following the 60 -sec struggle, subjects laid quietly on the mattress for $5 \mathrm{~min}$ to recover while expired air continued to be analyzed. Before each test, the gas analyzers and pneumotachometer were calibrated. HR was monitored using a telemetry transmitter attached to the chest (Polar Electronics, Kempele, Finland). All measurements were recorded as the average of 15 -sec intervals.

For comparison, the same cardiopulmonary parameters were measured during a maximal treadmill test. On a separate day, subjects performed a treadmill test at $1.61 \mathrm{~m} / \mathrm{sec}$ while cardiopulmonary functions were measured. The initial elevation was $0 \%$ and was increased $2 \%$ every minute until the subject reached volitional fatigue. Verbal encouragement was also provided during testing. The criteria for reaching $\dot{V} \mathrm{O}_{2 \max }$ were achieving: (1) a plateau in $\dot{V} \mathrm{O}_{2}( \pm 2 \mathrm{~mL} / \mathrm{kg} / \mathrm{min})$; (2) an $\mathrm{HR} \pm 15 \mathrm{bpm}$ of the agepredicted maximal $\mathrm{HR}$; and/or (3) a respiratory exchange ratio (RER) of 1.10 or above. All subjects achieved at least two of the criteria.

\section{Statistics}

To analyze the effect of the PMRP and weight force on MVV, a one-way repeated measures ANOVA was conducted. Post hoc Bonferroni's $t$-tests were used to follow up significant differences. $\alpha$ was set at 0.05 for all tests of significance. All statistical analyses were performed using SPSS v. 11.0 (SPSS Inc., Chicago, IL). Ninety-five percent confidence intervals $\left(\mathrm{CI}_{95}\right)$ were calculated to compare MVV values in the various positions with the predicted MVV and to MVV measured in the seated position. To analyze cardiopulmonary measurements during maximal struggle, we compared $\dot{V} \mathrm{O}_{2}$ during PRMP struggle with $\dot{V} \mathrm{O}_{2 \max }$ to assess the impact of restraint on oxygen consumption. In addition, we compared $\dot{V}_{\mathrm{E}}$ and $\dot{V}_{\mathrm{E}}$ /MVV ratio to assess ventilatory capacity and reserve during PRMP struggle and the maximal treadmill test.

\section{Results}

Thirty subjects ( 15 men and 15 women) completed the first part of the study examining the effects of the PMRP and weight on MVV. Data from two subjects were excluded from the study 
TABLE $1-$ Subject characteristics (mean $\pm S D$ ).

\begin{tabular}{lccc}
\hline & Total $(n=30)$ & Men $(n=15)$ & Women $(n=15)$ \\
\hline Age (year) & $24.5 \pm 3.5$ & $25.0 \pm 4.2$ & $28.9 \pm 6.2$ \\
Weight $(\mathrm{kg})$ & $72.6 \pm 14.2$ & $81.4 \pm 13.9$ & $63.9 \pm 7.3$ \\
Height $(\mathrm{m})$ & $1.72 \pm 0.09$ & $1.76 \pm 0.10$ & $1.67 \pm 0.06$ \\
BMI & $24.5 \pm 3.5$ & $26.1 \pm 3.5$ & $22.9 \pm 2.7$ \\
\hline
\end{tabular}

because they were psychologically unable to tolerate restraint (neither subject left the trial for any complaint other than they were frightened of being restrained. Both these subjects elected to withdraw from the study before the exercise period commenced and before any data were collected). Subject characteristics are presented in Table 1. All subjects were healthy and at least moderately active $\left[\dot{V} \mathrm{O}_{2 \max }=50.2 \pm 7.8 \mathrm{~mL} / \mathrm{kg} / \mathrm{min}\right.$; body mass index $(\mathrm{BMI})=24.5 \pm 3.4]$. Overall, $50 \%$ of the subjects weighed less than $68 \mathrm{~kg}$, which included 12 women and three men.

\section{Part 1-Position and Weight Effects on MVV}

The results of the MVV measurements under various conditions are presented in Table 2. Because there was a significant departure from sphericity $(p=0.001 ; \varepsilon=0.646)$, Greenhouse-Geisser adjusted values were used to evaluate the significance of the main effects. Confidence intervals that included $100 \%$ were not considered different from the predicted or the seated MVV. MVV in the seated position was $156 \pm 38 \mathrm{~L} / \mathrm{min}$, which was $122 \%$ higher than predicted $\left(\mathrm{CI}_{95}=104-140\right)$. Conversely, MVV while prone with the HW was lower $(85 \%)$ than predicted $\mathrm{MVV}\left(\mathrm{CI}_{95}=72-98\right)$.

All measured MVVs differed from each other $(p<0.001)$, except the comparison of the PMRP and MW trials. MVVs of the treatment trials were also compared with the seated MVV. MVV of the PMRP trial and when prone with MW and HW were significantly less than the seated $\mathrm{MVV}$, although the $\mathrm{CI}_{95}$ from the LW trial suggested no difference from the seated MVV $\left(\mathrm{CI}_{95}=77-100\right)$.

\section{Part 2-Cardiopulmonary Measurements During Maximal Struggle}

Valid data were obtained from only 27 subjects for this part of the study. The struggle was physically difficult for subjects. In spite of continued verbal encouragement, the intensity of movement was visibly waning in all subjects by the end of the 60sec trial. This was supported by the RER-calculated as $\dot{V} \mathrm{CO}_{2}$ : $\dot{V} \mathrm{O}_{2}$ - that averaged $1.16 \pm 0.14$. Only one subject, a female, failed to achieve an RER greater than 1.05 during the maximal

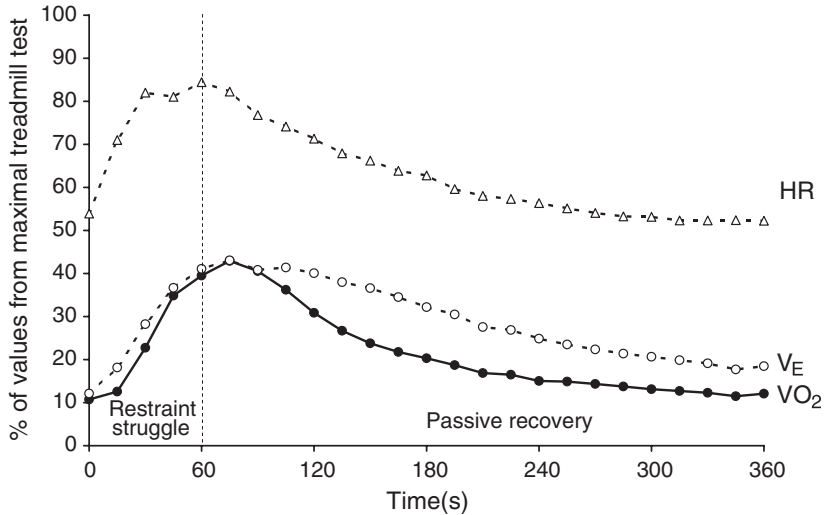

FIG. 2-Percent differences of cardiopulmonary values from peak treadmill values during and after the restrained struggle trial.

restrained struggle. Values in excess of 1.0 indicated that an individual was hyperventilating, and the values observed at the end of the maximal struggle were similar to those observed at the end of their maximal treadmill test $(1.21 \pm 0.07)$. At the end of the struggle, $\dot{V} \mathrm{O}_{2}$ and $\dot{V}_{\mathrm{E}}$ were $40 \%$ and $42 \%$, respectively, of the peak values achieved during the maximal treadmill test (Fig. 2). Also, $\mathrm{HR}$ at the end of the struggle was $84 \%$ of peak HR from the treadmill test. The $\dot{V}_{\mathrm{E}} / \mathrm{MVV}$ ratios (using MVV measured in the seated position) of peak $\dot{V}_{\mathrm{E}}$ during the treadmill test and at the end of the restrained struggle were $89 \%$ and $44 \%$, respectively (Table 3).

\section{Discussion}

Although sudden death has occurred in individuals placed in the PMRP, the cause of death and whether body position was a factor remain controversial. Some have suggested that PMRP prevents adequate chest wall, abdominal, and diaphragmatic movement, leading to hypoventilatory respiratory compromise and risk for death from positional asphyxia $(8,18)$. Prior studies in healthy subjects have found no evidence of significant hypoventilation when subjects were placed in the PMRP $(2,8)$. Our results in this study appear to support these findings. MVV in all of the treatment conditions remained above $80 \%$ of predicted, well within the normal range $(19,20)$.

While by itself the PMRP does not appear to compromise ventilatory capacity unduly, the restraining process also frequently includes applying force to the back. Weight applied in the prone position has been hypothesized to further compress the chest and

TABLE 2-Measured MVV values $(n=30)$.

\begin{tabular}{|c|c|c|c|c|c|c|}
\hline \multirow[b]{2}{*}{ Position } & \multicolumn{2}{|c|}{ MVV (L/min) } & \multicolumn{2}{|c|}{ Percentage of Seated MVV } & \multicolumn{2}{|c|}{ Percentage of Predicted MVV } \\
\hline & Mean $\pm \mathrm{SD}$ & Range & $\%$ & $\mathrm{CI}_{95}$ & $\%$ & $\mathrm{CI}_{95}$ \\
\hline Seated & $156 \pm 38$ & $75-243$ & - & - & 122 & $104-140$ \\
\hline PMRP & $128 \pm 29$ & $65-193$ & $82 *$ & $68-96$ & 100 & 99-102 \\
\hline LW & $137 \pm 27$ & $85-189$ & 88 & $77-100$ & 107 & $97-117$ \\
\hline MW & $122 \pm 31$ & $61-197$ & $78^{*}$ & $64-93$ & 95 & $87-103$ \\
\hline HW & $109 \pm 28$ & $57-167$ & $70^{*}$ & $54-86$ & $85^{\dagger}$ & $72-98$ \\
\hline
\end{tabular}

*Below MVV measured in the seated position.

${ }^{\dagger}$ Below predicted MVV.

Note: All measured MVV values differed from each other except for the PMRP and MW comparison $(p<0.001)$. PMRP, prone maximal restraint position; LW, prone position with low weight ( 22.7 or $34.1 \mathrm{~kg}$ ) applied on subject's back; MW, prone position with moderate weight $(56.8 \mathrm{or} 68.2 \mathrm{~kg})$; HW, prone position with heavy weight ( 90.2 or $102.3 \mathrm{~kg}$ ); MVV, maximal voluntary ventilation. For the three conditions in which weight was placed on the back, the lighter weight was used for subjects who weighed less than $68 \mathrm{~kg}(n=15)$ and the heavier weight for those who weighed more than $68 \mathrm{~kg}(n=15)$. 
TABLE 3-Cardiopulmonary peak values during maximal treadmill test and at the end of the restrained struggle $(n=27)$.

\begin{tabular}{lcclcc}
\hline & \multicolumn{2}{c}{ Treadmill } & & \multicolumn{2}{c}{ Restrained Struggle } \\
\cline { 2 - 3 } \cline { 5 - 6 } & Mean \pm SD & Range & & Mean \pm SD & Range \\
\hline$\dot{V} \mathrm{O}_{2}(\mathrm{~mL} / \mathrm{kg} / \mathrm{min})$ & $50.2 \pm 7.8$ & $29.1-65.8$ & & $19.8 \pm 5.4$ & $11.6-30.9$ \\
$\dot{V}_{\mathrm{E}}(\mathrm{L} / \mathrm{min})$ & $140.1 \pm 36.7$ & $84.2-206.5$ & & $57.6 \pm 23.3$ & $29.4-113.3$ \\
$V_{\mathrm{T}}(\mathrm{L})$ & $2.8 \pm 0.7$ & $1.8-4.7$ & & $1.0 \pm 0.4$ & $0.6-2.3$ \\
$\mathrm{RR}(\mathrm{breaths} / \mathrm{min})$ & $56 \pm 8$ & $39-70$ & & $60 \pm 14$ & $35-88$ \\
$\mathrm{HR}($ beats/min $)$ & $190 \pm 12$ & $166-221$ & & $160 \pm 19$ & $105-196$ \\
$\mathrm{RER}$ & $1.21 \pm 0.07$ & $1.09-1.35$ & & $1.16 \pm 0.14$ & $0.92-1.35$ \\
\hline
\end{tabular}

HR, heart rate; RER, respiratory exchange ratio.

abdomen, which might lead to hypoventilatory respiratory compromise (15) and diminished ventilatory function to the point of asphyxiation (20). One of the goals of this paper was to isolate the effects of weight applied in the prone position. Our results indicated that with $90.2-102.3 \mathrm{~kg}$ of weight applied to the back of our subjects, MVV was decreased to $85 \%\left(\mathrm{CI}_{95}=72-98\right)$ and $70 \%$ $\left(\mathrm{CI}_{95}=54-86\right)$ of the predicted and previously measured MVVs, respectively. Despite these decreases, these MVVs are still within published $\mathrm{CI}_{95}$ for men (12) and women (14).

Even though the decreases in pulmonary function as a result of weight force applied to the back remain with the normal clinical parameters for a healthy person at rest, the circumstances of PMRP-related sudden death cases are very different. Sometimes, the victim has been involved in high-intensity exercise (e.g., running, fighting) before being restrained and, afterwards, will continue to resist the restraint violently. It has been suggested that under these circumstances, oxygen consumption may exceed ventilatory capacity in individuals placing them at risk for respiratory compromise (21). As such, we also measured $\dot{V} \mathrm{O}_{2}$ and $\dot{V}_{\mathrm{E}}$ while in the PMRP and compared them with similar measurements from maximal treadmill tests. Our results indicated that with maximal struggle while in the PMRP, $\dot{V} \mathrm{O}_{2}$ and $\dot{V}_{\mathrm{E}}$ were less than $42 \%$ of peak values obtained from a maximal treadmill test. In general, the most metabolically and ventilatory demanding type of exercise resulting in the highest $\dot{V} \mathrm{O}_{2}$ occurs when large muscle groups work in a rhythmic fashion (e.g., running, cycling). It is likely that PRMP limits subjects from using these large muscle groups in rhythmic movements, thus resulting in the low $\dot{V} \mathrm{O}_{2}$ and $\dot{V}_{\mathrm{E}}$ we observed.

Ventilatory constraint is often determined by measuring how close $\dot{V}_{\mathrm{E}}$ at maximal exercise intensity approaches MVV (18). At $\dot{V} \mathrm{O}_{2 \max }$, individuals with normal lung function ventilate at 60 $70 \%$ of their MVV (22). Accordingly, in our study, the peak $\dot{V}_{\mathrm{E}} /$ MVV during the maximal treadmill test was $72 \%$ of the measured MVV. On the other hand, during PRMP struggle, $\dot{V}_{\mathrm{E}} / \mathrm{MVV}$ was only $36 \%$ of the measured MVV. Our findings of clinically normal MVVs with PMRP and prone weight in phase 1, as well as the lower $\dot{V} \mathrm{O}_{2}$ and $\dot{V}_{\mathrm{E}} / \mathrm{MVV}$ during PRMP struggle suggest that our subjects appeared to have adequate ventilatory reserve when struggling while restrained. Furthermore, the extremely low $\dot{V}_{\mathrm{E}} /$ MVV ratio at the end of maximal struggle, compared with the actual MVV measured with weight on the back, suggests that should weight be applied while individuals were in the PMRP it would be well tolerated as well. Clearly, this remains to be proven in future studies.

Based on these findings, as well as previously published studies, we suggest that factors other than ventilatory failure associated with the restraining process may be responsible for the sudden unexpected deaths of restrained individuals. Although autopsy evidence is often unrevealing as to the cause of the death, those individuals who die at times seem to succumb suddenly (23), which is a pattern generally inconsistent with a respiratory death. Some individuals have been reported to die suddenly while restrained without force applied to the back $(6,7,10,23)$, restrained in a supine, sitting, or side position $(9,17)$, or even without being restrained (24). Other factors, such as excited delirium, drug intoxication, stress, trauma, and catecholamine hyperstimulation, are considered to be the most likely factors in these sudden deaths $(2,3,19)$. In addition, studies indicate that many of these individuals have an abnormally enlarged heart on autopsy, likely related to chronic stimulant drug abuse (5). Not only is there a greater risk for cardiac dysrhythmias and sudden death in those with cardiomyopathy, but recent investigations suggest that individuals with this condition have decreased capillary density in their endocardium, placing them at risk for chronic and perhaps acute cardiac ischemia (25). Our results, as well as those of others $(2,3,15)$, suggest that in deaths associated with the PMRP, factors other than ventilatory compromise may play a more important role.

Clearly, this study has a number of limitations. First, our subjects were young and generally healthy and may not reflect the population of individuals who are restrained in the field setting. It should be noted that the baseline-measured MVVs of subjects were $122 \%$ of predicted, suggesting that our subjects were both highly motivated, and had a high aerobic fitness level (26). In the actual field setting, underlying medical conditions and other differences from our subject population (e.g., age, weight, etc.) might theoretically influence the outcome.

Second, we could not reproduce all conditions during which this type of restraint method is used in the field. In particular, while we had subjects restrained and maximally exerting themselves, we could not reproduce the psychological or other physiologic stresses associated with a field pursuit, struggle, or trauma). During the trials with weight applied to the back, the weight was distributed evenly over the back, unlike in a field situation in which force is applied to the back frequently with a knee that focuses the force over a smaller area. In addition, a small number of our subjects did opt out of the study out of fear of the restraint. Clearly, in the field setting, individuals are unlikely to have such a choice as to whether they are restrained or not; however, it is difficult to understand how such factors might affect ventilation.

Therefore, how such factors may or may not contribute to these deaths will require future study; however, an animal model suggests that restraint alone (without affecting an animal's ability to breathe) increases the death rate in animals treated with cocaine (27). This implies that the physiologic effects of restraint involve more than ventilation alone, which is consistent with the results of this and prior studies $(3,11)$. Second, we placed weight on subjects' back when MVV was measured in the prone position, but no force was applied on subjects when positioned in the PMRP. Such a model has its limitations and does not necessarily duplicate the sequence of events that may take place in any given field situation; however, we do feel this represents a first step in investigating a very complex arena. Third, the exertion and struggle of our subjects in PMRP was of short duration and also may not reflect a field situation where prolonged struggles can occur. Furthermore, our subjects exerted themselves on a voluntary basis, although they were verbally encouraged by the investigators to struggle as much as possible throughout the 1-min period. This voluntary nature may not exactly reflect field situations where individuals are often under the influence of drugs or are mentally incapacitated. On the other hand, our subjects did exercise to exhaustion or near 
exhaustion and their significantly increased HR suggests high levels of exertion on their part.

Finally, of course, none of our subjects used illicit drugs. However, none of the illicit drugs frequently used in the setting we are trying to simulate have an effect upon ventilation and therefore it appears to be more likely that the role such drugs play in these deaths is through some other mechanism than their effect upon ventilation. There are other factors in the field that that are also different from our setting that might theoretically affect our results (e.g., a gymnastic mat rather than the actual outside surface, and the even distribution of the weight force we used across the back rather than it being localized to a smaller area); however, it will await future studies to determine whether these factors play any role in such deaths.

In summary, this study attempted to investigate the impact of varying weight force upon the back in healthy individuals in the prone position. We recognize the differences between the laboratory setting and actual field conditions; nonetheless, we found no clinically important restriction of ventilatory reserve when subjects were placed in the PMRP or when prone with up to 90.2 or $102.3 \mathrm{~kg}$ of weight on their back. Likewise, when subjects were maximally struggling for $60 \mathrm{sec}$ while in the PMRP, there were no clinically important limitations of metabolic or ventilatory functions. Based on these observations in healthy subjects, we conclude that PMRP and prone positioning with moderate weight force on the back do not in and of themselves restrict metabolic or ventilatory demands to any clinically important degree. As such, factors other than isolated ventilatory failure should be considered when evaluating deaths occurring in the setting of restraint in the field.

\section{Acknowledgments}

The authors wish to acknowledge the contribution of Mohammed Najeed, RT, UCSD Medical Center, for performing the MVV measurements in this study.

This study was funded in part by an unrestricted grant from the University of California, San Diego, Department of Emergency Medicine Research Fund. Portions of this study were presented at the Society for Academic Emergency Medicine, New York, NY, May 2005.

\section{References}

1. Chan TC, Vilke GM, Neuman T. Reexamination of custody restraint position and positional asphyxia. Am J Forensic Med Pathol 1998;19:201-5.

2. Chan TC, Vilke GM, Neuman T. Restraint position and positional asphyxia. Am J Forensic Med Pathol 2000;21:3.

3. Chan TC, Neuman T, Clausen J, Eisele J, Vilke GM. Weight force during prone restraint and respiratory function. Am J Forensic Med Pathol 2004;25:185-9.

4. Eisele J, Chan T, Vilke G, Neuman T, Clausen J. Comparison of respiratory function in the prone maximal restraint position with and without additional weigh force on the back. In: Proceedings of the 52nd annual meeting of the American Academy of Forensic Sciences; 2000. February 21-26; Reno, NV. Colorado Springs, CO: American Academy of Forensic Sciences, 2000.
5. Schmidt $P$, Snowden $T$. The effects of positional restraint on heart rate and oxygen saturation. J Emerg Med 1999;17:777-82.

6. Pollanen MS, Chiasson DA, Cairns JT, Young JG. Unexpected death related to restraint for excited delirium: a retrospective study of deaths in police custody and in the community. Can Med Assoc J 1998;158:1603-7.

7. Reay DT, Fligner CL, Stilwell AD, Arnold J. Positional asphyxia during law enforcement transport. Am J Forensic Med Pathol 1992;13:90-7.

8. Stratton SJ, Rogers C, Brickett K, Gruzinski G. Factors associated with sudden death of individuals requiring restraint for excited delirium. Am J Emerg Med 2001;19:187-91.

9. Ross DL. Factors associated with excited delirium deaths in police custody. Mod Pathol 1998;11:1127-37.

10. O'Halloran RL, Frank JG. Asphyxial death during prone restraint revisited: a report of 21 cases. Am J Forensic Med Pathol 2000;21:39-52.

11. Chan TC, Vilke GM, Neuman T, Clausen L. Restraint positional asphyxia. Ann Emerg Med 1997;30(5):578-86.

12. Lifschultz BD, Donoghue ER. Deaths in custody. In: Welch C, editor. Legal Medicine annual. Salem, NH: Butterworth; 1991:45-70.

13. Mittleman R, Davis J. Deaths from custody? Forensic Pathol 1991; 22(2):98.

14. Reay DT, Howard JD. Restraint position and positional asphyxia. Am J Forensic Med Pathol 1999;20:300-1.

15. Reay DT. Death in custody. Clin Lab Med 1998;18:1-22.

16. American Thoracic Society. Standardization of spirometry, 1994 update. Am J Respir Crit Care Med 1995;152:1107-36.

17. Bass H. The flow volume loop: normal standards and abnormalities in chronic obstructive pulmonary disease. Chest 1973;63:171-6.

18. Johnson BD, Weisman IM, Zeballos JR, Beck KC. Emerging concepts in the evaluation of ventilatory limitation during exercise: the exercise tidal flow loop. Chest 1999;116:488-503.

19. Kory RC. The VA Administration-army cooperative study of pulmonary function I: clinical spirometry in normal men. Am J Med 1961;30: 243-58.

20. Lindall A, Medina A, Grisner JT. A re-evaluation of normal pulmonary function measurements in the adult female. Am Rev Resp Dis 1967;95:1061-4.

21. Parkes J. Sudden death during restraint: a study to measure the effect of restraint positions on the rate of recovery from exercise. Med Sci Law 2000;40:39-44.

22. Stratton SJ, Rogers C, Green K. Sudden death in individuals in hobble restraints during paramedic transport. Ann Emerg Med 1995;25: $710-2$.

23. Hick JL, Smith SW, Lynch MT. Metabolic acidosis in restraint-associated cardiac arrest: a case series. Acad Emerg Med 1999;6:239-43.

24. Ruttenber AJ, Lawler-Heavner J, Yin M, Wetli CV, Hearn WL, Mash DC. Fatal excited delirium following cocaine use: epidemiologic findings provide new evidence for mechanisms of cocaine toxicity. J Forensic Sci 1997;42(1):25-31.

25. Karch R, Neumann F, Ullrich R, Neumuller J, Podesser BK, Neumann M, et al. The spatial pattern of coronary capillaries in patients with dilated, ischemic, or inflammatory cardiomyopathy. Cardiovasc Pathol 2005;14: $135-44$.

26. Babb TG, Rodarte JR. Estimation of ventilatory capacity during submaximal exercise. J Appl Physiol 1993;74(4):2016-22.

27. Pudiak CM, Bozarth MA. Cocaine fatalities increased by restraint stress. Life Sci 1994;55(19):379-82.

Additional information and reprint requests:

Fred W. Kolkhorst, Ph.D.

Department of Exercise and Nutritional Sciences

San Diego State University

5500 Campanile Drive

San Diego

CA 92182-7251

E-mail: fred.kolkhorst@sdsu.edu 